\title{
Application of Pressure-Sensitive Paint to Low-Speed Flow around a U-Bend of Strong Curvature
}

Link to publication record in Manchester Research Explorer

\section{Citation for published version (APA):}

Quinn, M. K., Gongora-Orozco, N., Kontis, K., \& Ireland, P. (2011). Application of Pressure-Sensitive Paint to LowSpeed Flow around a U-Bend of Strong Curvature. In host publication

\section{Published in:}

host publication

\section{Citing this paper}

Please note that where the full-text provided on Manchester Research Explorer is the Author Accepted Manuscript or Proof version this may differ from the final Published version. If citing, it is advised that you check and use the publisher's definitive version.

\section{General rights}

Copyright and moral rights for the publications made accessible in the Research Explorer are retained by the authors and/or other copyright owners and it is a condition of accessing publications that users recognise and abide by the legal requirements associated with these rights.

\section{Takedown policy}

If you believe that this document breaches copyright please refer to the University of Manchester's Takedown Procedures [http://man.ac.uk/04Y6Bo] or contact uml.scholarlycommunications@manchester.ac.uk providing relevant details, so we can investigate your claim.

\section{OPEN ACCESS}




\title{
APPLICATION OF PRESSURE-SENSITIVE PAINT TO LOW-SPEED FLOW AROUND A U-BEND OF STRONG CURVATURE
}

\author{
Quinn, M. K., ${ }^{* 1}$ Gongora-Orozco, $N .{ }^{* 1}$ Kontis, $K .{ }^{* 1}$ and Ireland, $P .{ }^{* 2}$ \\ *1 Aero-Physics Laboratory, School of MACE, The University of Manchester M60 1QD, UK \\ *2 Rolls-Royce Associate Fellow, Thermofluids Turbine SCU, Rolls-Royce plc \\ E-mail: mark.quinn-2@postgrad.manchester.ac.uk
}

\begin{abstract}
Two in-house Pressure-Sensitive Paint (PSP) formulations have been developed and tested in the low-speed regime on the flow around a U-bend of strong curvature. The two PSP formulations use trisBathophenanthroline Ruthenium Perchlorate (Ru (II)) and Platinum tretakis (pentafluorophenyl) Porphyrin (PtTFPP) as their photoactive molecules, incorporated in identical sol-gel matrices. Ru (II) emits a broad peak centered at $610 \mathrm{~nm}$ while PtTFPP emits a much narrower peak at $650 \mathrm{~nm}$. The paints were illuminated using two in-house constructed blue LED lights with peak emission of $468 \mathrm{~nm}$. These luminophores have been tested with gauge inlet pressures of 3000 and $1250 \mathrm{~Pa}$ respectively. A further sample was tested with a gauge pressure of 500 $P a$. In-situ calibration was utilized to minimize the temperature dependency change between wind-on and wind-off images. Both paints captured the flow characteristics and gave predictable surface pressure maps despite the challenges inherent with using such low pressures.
\end{abstract}

\section{Keywords: PSP, low-speed, U-bend, internal flow}

\section{INTRODUCTION}

Several researchers have attempted to use pressuresensitive paints (PSP) at low speeds despite the inherent difficulties with such applications $[1,2,3,4,5,6,7]$. Of these researchers Bell [3] and Le Sant [7] managed extremely low errors $( \pm 50 \mathrm{~Pa})$. However, all of the applications of PSP to low-speed flow have been performed in large-scale wind tunnels. To this end it was decided to test the PSP formulations in use at the University of Manchester on a low-speed, internal flow.

\section{Flow Around U-Bend}

The flow around a rectangular cross-section U-bend with strong curvature is well understood and has been researched thoroughly by numerous academics. This type of flow has many engineering applications such as internal cooling flow in gas turbine blades and efficiency analysis of refrigeration cycles. The flow into the bend is subject to a pressure gradient which causes the flow to accelerate inwards. This pressure gradient is strong enough to reverse the slow moving fluid creating secondary flows [8] as the fluid streamlines are not parallel to the pressure gradient. This three-dimensionality has been explored in depth in computational studies by Iacovides et al. [9]. It has been shown that the pressure drop around the bend is dependent on the presence of separation at the inner wall of the bend, the strength of the three-dimensionality and its associated losses [10]. The defining parameter of the pressure drop (assuming similar inlet flow conditions) is the relative radius of curvature or radius rate [11].

The flow around a U-bend has been optimized by changing the inner wall shape using an iterative Design of Experiment method by Namgoong et al. [12]. This paper shows how incompressible flow around a U-bend can be optimized by changing various geometric parameters around the bend to control separation and therefore reduce the total pressure loss, lowering the operating pressure required. In the current paper, the baseline case investigated by Namgoong et al. will be tested using PSP.

\section{Pressure-Sensitive Paint}

Traditionally, surface pressures are measured using multiple pressure taps connected to transducers. It is not uncommon for a large-scale model to contain 100 (or more) of these taps which can be very expensive and time consuming to install. This method of measuring surface pressure only yields discrete measurements and can miss small-scale fluctuations. However, PSP allows for the measurement of pressure across an entire surface, giving a reduction in cost and manpower and an increase in spatial resolution.

PSP is based on the theory of oxygen quenching which involves the non-radiative deactivation of an excited photo-active molecule (luminophore). This process has been theoretically described by numerous researchers but was most clearly illustrated in the book by Lui and Sullivan [13]. For the sake of brevity, only a brief recollection of the theory will be repeated here.

A luminophore is excited to an electronic state higher than its ground state by absorbing a specific wavelength of light. This excited luminophore returns to its ground state by either a radiative or non-radiative process. Radiative processes include fluorescence and phosphorescence (these processes are grouped together under the term of luminescence). Non-radiative processes include internal conversion and then the release of heat or external conversion via contact with an external molecule, in this case oxygen. Oxygen is an extremely good quenching molecule as it has an unusual electronic ground configuration which is easily excited [14]. Henry's law states that, at a constant temperature, the amount of gas dissolved in a solid is proportional to the pressure of the gas at the surface. When combined with Dalton's law of partial pressures, this means that the amount of oxygen in the polymer layer can be calculated. However, rather than taking one absolute measurement, intensity based PSP involves taking a reference image, a test image and dividing the two. This has the advantage that it helps to eliminate spatial variation of luminophore concentration on the painted surface. The pixel-by-pixel intensity ratio 
can be related to the pressure on the surface at that point by the well-known Stern-Volmer equation:

$$
\frac{I_{r e f}}{I}=A(T)+B(T) \frac{P}{P_{r e f}}
$$

The coefficients in this equation are temperature dependant, giving rise to the largest error present in PSP measurements: temperature-induced error.

As the flow seen here is steady and low-speed, polymerbased PSP was used. The faster response offered by anodized PSP was deemed to be unnecessary. Polymerbased PSP has the luminophore suspended in a highly porous polymer matrix.

Of the two methods of calibrating PSP, in-situ calibration was used in this experiment, as it intrinsically takes into account photodegradation and humidity effects. Providing the temperature change between wind-on and wind-off images is a discrete step, with no spatial variation, the temperature induced error can be calibrated out too [1].

\section{EXPERIMENTAL SETUP}

The experimental setup used is shown in Fig. 1. The Ubend is made of stereo-lithography material with one face made of Perspex to give optical access to the far wall. Removable aluminum plates with pressure taps drilled in them were prepared with the different PSP recipes and attached to the far wall. A typical raw image showing the numbering of the pressure taps is shown in Fig. 2. The PSP was excited using two in-house built LED lamps with emission peaks at $468 \mathrm{~nm}$. This wavelength was chosen so that both luminophores can be excited using the same lamp. However, it should be noted that $468 \mathrm{~nm}$ is not the peak excitation wavelength of PtTFPP.

The imaging device used to capture the emission wavelength was the LaVision Imager Intense CCD camera with a $600 \mathrm{~nm}$ long pass filter and an IR cut-off. The Imager Intense has a quantum efficiency of $45 \%$ at $610 \mathrm{~nm}$ and $35 \%$ at $650 \mathrm{~nm}$. This is one of the limiting factors affecting the signal measured by the CCD.

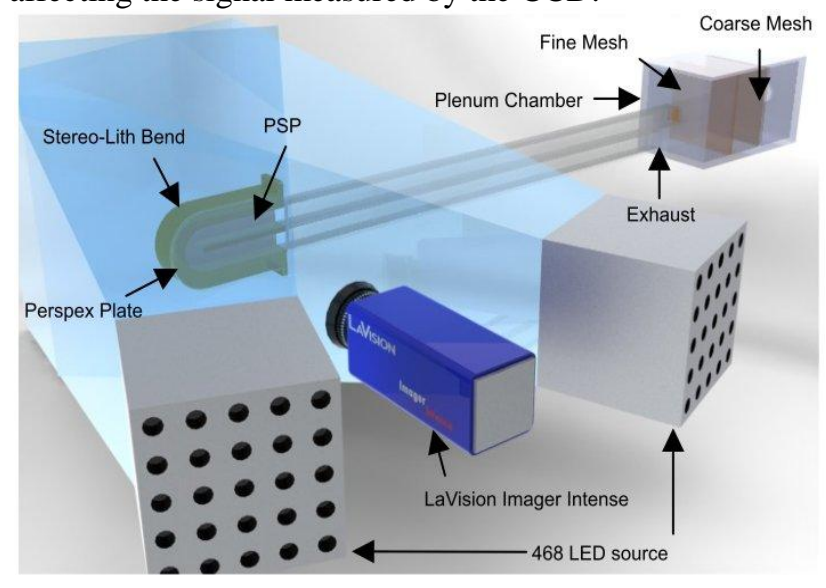

Fig. 1. Experimental setup

The rig was fed into the plenum chamber using an inhouse supply of compressed air. The plenum gauge pressure was measured using a digital differential manometer (TT370S) manufactured by DP Measurement LTD. This manometer has a dynamic range of $\pm 2000 \mathrm{~Pa}$ with an accuracy of greater than $1 \%$.

In order to minimize possible temperature gradients in the sample, the experimental rig was left to run for approximately 20 minutes [15]. This allowed the rig to reach thermal equilibrium before capturing the wind on image. The wind off image was captured immediately after shutdown to reduce temperature-induced errors as the test rig returned to ambient temperature.

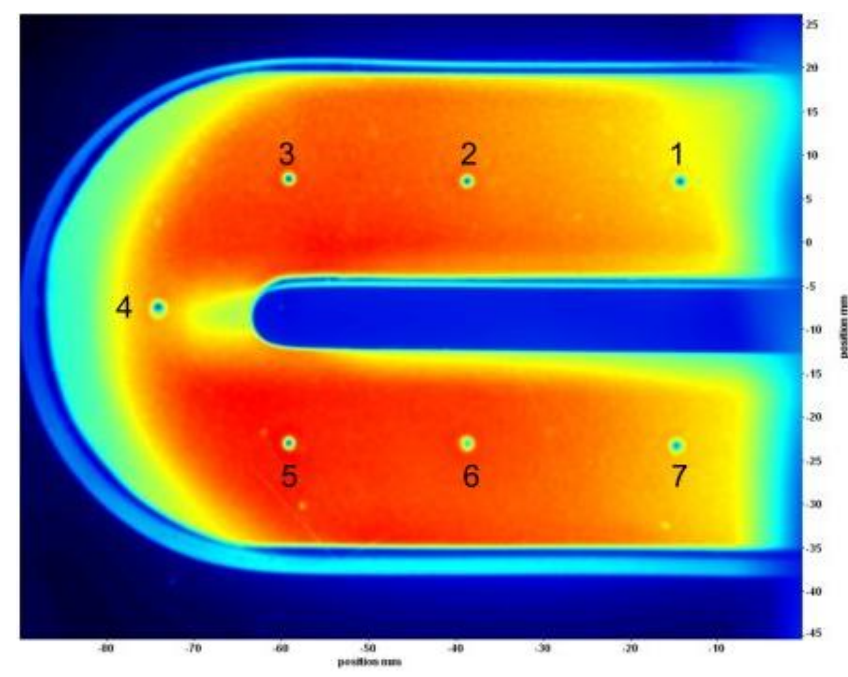

Fig. 2. Typical raw image showing pressure tap numbering and centerline

\section{PSP Preparation}

The aluminum plate samples were prepared by applying 3 basecoats of Ambersil matt white acrylic paint Ral9010 to give a uniform reflective surface on which to apply the PSP. Brown [1] showed that surface roughness has a severe impact on the performance of PSP, so ensuring a uniform surface was crucial. To obtain a smooth finish the base coat was sanded with various grades of abrasive paper. The surface roughness was measured before and after application of the PSP using the Taicaan XYris 4000 surface roughness profiler, the results of which will be discussed in section 3.1.

Both PSP formulations used Methyl triethoxysilane (MTEOS) as the sol-gel binder, as it is known to have excellent oxygen permeability and good adhesion [15]. The only difference between the different PSP formulations is the luminophore, allowing for direct comparison of their performance at low pressures. The ruthenium based PSP is the same recipe used by ZareBehtash et al. [17].

The PSP was applied in 7 light coats to the prepared basecoat using a modeler's airbrush. A fast sweeping action was used to ensure uniformity and each coat was allowed to dry for approximately 2 minutes before application of subsequent coats. The preparation of the 
samples took place in as dark an environment as possible so as not to photodegrade the paint. Immediately after the PSP had been applied the sample was cured in an oven at $343 \mathrm{~K}$ for 7 hours.

After application of 7 coats of PtTFPP based PSP, the surface did not seem uniform as the PSP had agglomerated together into lumps giving a rough finish. In order to improve on this a second PtTFPP sample was prepared using significantly finer coats (16 in total) until the color of the previous sample was matched. This resulted in a much smoother appearance with no visible lumps of PSP.

\section{Data Collection}

When capturing PSP images it is important to ensure that the CCD is making use of its full-well capacity $(18,000$ electrons in this case) so as to maximize the signal-tonoise ratio. It is well known that $\mathrm{Ru}$ (II)-based paints give a larger signal at atmospheric pressure than PtTFPP but exhibit lower pressure sensitivity [13]. Therefore, in order to gather an acceptable signal level it was necessary to have an exposure time of $20,000 \mu$ s for $\mathrm{Ru}$ (II) and $100,000 \mu$ s for PtTFPP. Aside from this the rest of the data collection and image processing is identical for both PSPs. It has been found that the best way to collect PSP data is to average 32 images per run. ${ }^{1}$ Each of the 32 images had a dark image subtracted from them to account for the dark signal of the camera. These images are then averaged to create one image that is then masked to only contain the area of interest. A 5x5 linear filter is then applied to smooth the images and finally the wind-on and wind-off images are divided.

\begin{tabular}{|l|l|l|l|}
\hline Sample & $\begin{array}{l}\text { Basecoat before } \\
\text { sanding }(\mu \mathrm{m})\end{array}$ & $\begin{array}{l}\text { Basecoat after } \\
\text { sanding }(\mu \mathrm{m})\end{array}$ & $\begin{array}{l}\text { PSP } \\
(\mu \mathrm{m})\end{array}$ \\
\hline $\begin{array}{l}\text { Ru(II) } \\
(7 \text { Coats })\end{array}$ & \pm 0.947 & \pm 0.847 & \pm 0.527 \\
\hline $\begin{array}{l}\text { PtTFPP } \\
\text { first } \\
\text { sample } \\
\text { (7 Coats) }\end{array}$ & \pm 0.938 & \pm 0.889 & \pm 1.007 \\
\hline $\begin{array}{l}\text { PtTFPP } \\
\text { second } \\
\text { sample } \\
\text { (16 Coats) }\end{array}$ & \pm 0.950 & \pm 0.876 & \pm 0.231 \\
\hline
\end{tabular}

Table 1. Surface roughness characteristics

\section{RESULTS}

\section{Roughness}

The average surface roughness of the $\mathrm{Ru}$ (II) and both PtTFPP samples is presented in Table 1 below. This is

\footnotetext{
${ }^{1}$ The signal-to-noise ratio is not improved significantly by averaging more than 32 images and the extra acquisition time can increase temperature-induced errors (Brown 2000)
}

based on measuring 5 samples at random locations then averaging.

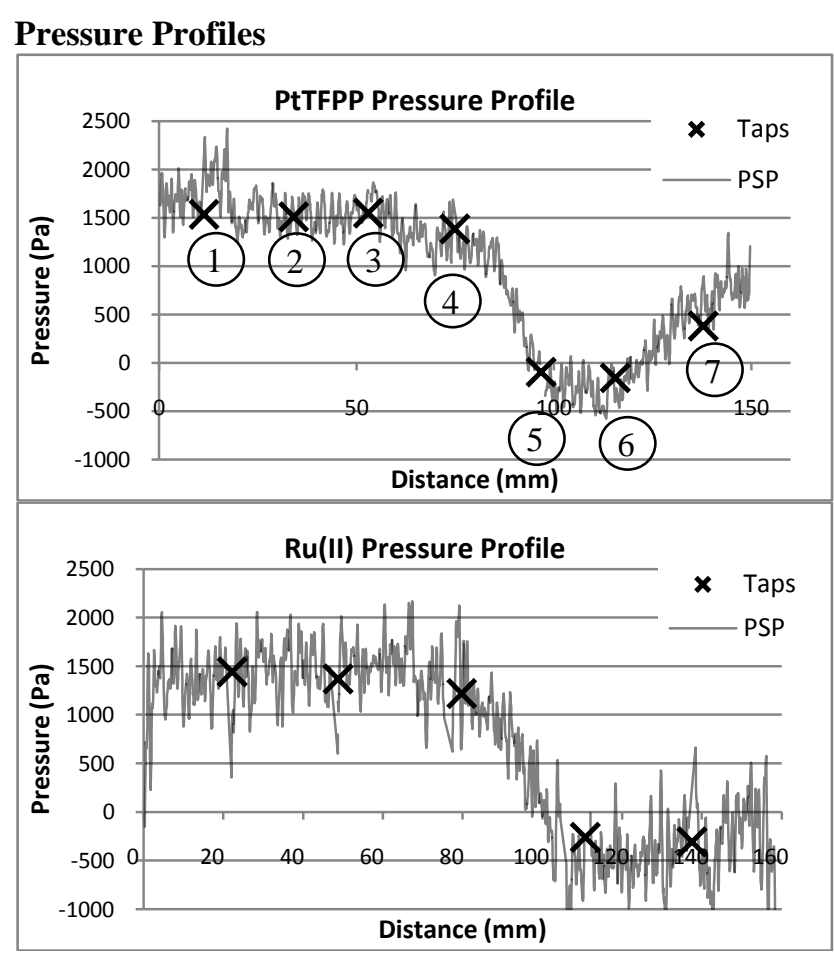

Fig. 3. $3000 \mathrm{~Pa}$ centerline pressure profiles

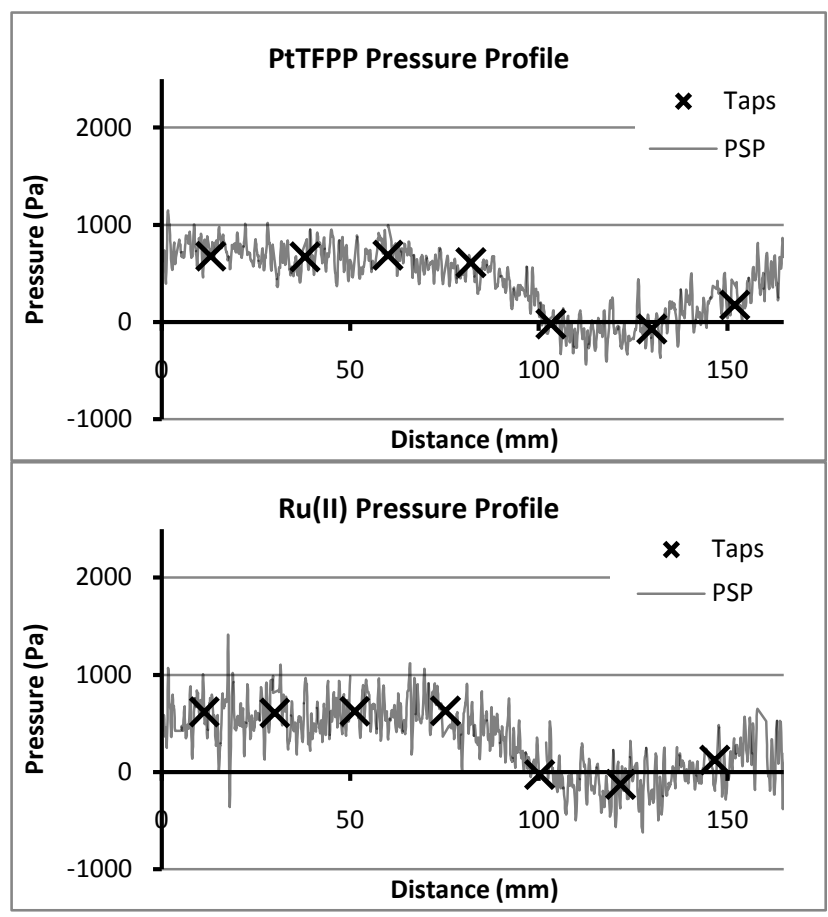

Fig. 4. $1250 \mathrm{~Pa}$ centerline pressure profiles

\section{Initial Samples}

The images shown in Fig. 4 contain the centerline (see Fig.2) pressure profile around the bend with an inlet pressure of $3000 \mathrm{~Pa}$. 


\section{Second Sample}

Fig. 5 shows the centerline pressure profile using the second sample of PtTFPP at 3000, 1250 and $500 \mathrm{~Pa}$.

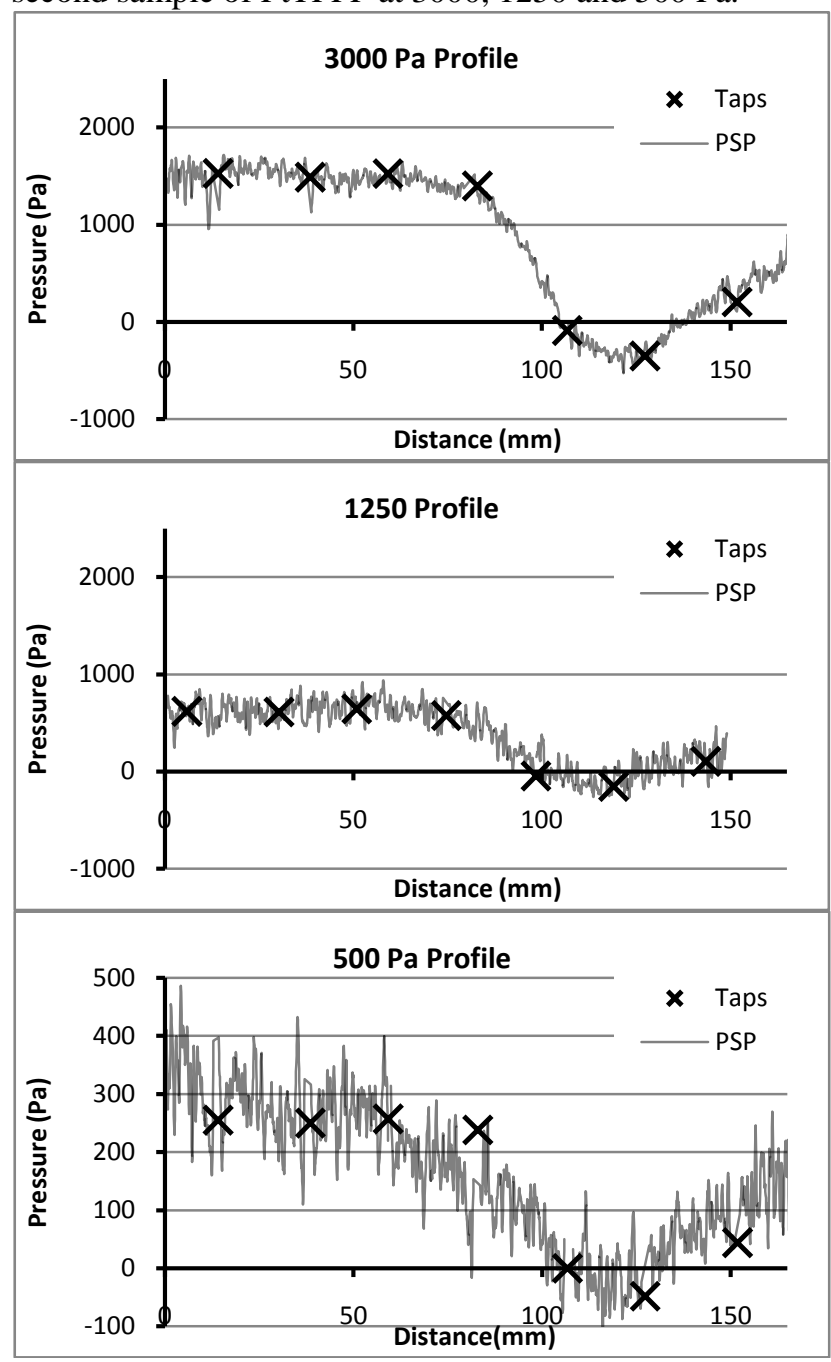

Fig. 5. Centerline pressure profiles for second PtTFPP sample at 3000, 1250 and $500 \mathrm{~Pa}$.

\section{DISCUSSION}

From Figs. 3 and 4 it is clear to see that both paints follow the pressure measured at the static tappings very well and give similar pressure magnitudes. There is a clear pressure drop around the bend and a modest pressure recovery shortly after. This can clearly be seen in Figs. 6 and 7, which is a typical pressure map obtained from the PSP measurements. Both Ru (II) and PtTFPP paints can be used to give quantitative pressure measurements even at such low pressures as used here.

Although both paints show the flow pattern well, there are some clear differences between them. The Ru (II)-based paint shows a higher degree of spatial noise compared to the initial PtTFPP sample. This seems to contradict the conclusion of Brown [1] as the surface of the initial PtTFPP sample is rougher than the sample of $\mathrm{Ru}$ (II). This can be accounted for by the fact that although the Ru (II) sample is smoother, its signal-to-noise ratio is lower than that of PtTFPP. This shows that although roughness may be a good parameter for characterizing the response of PSP it is not a good parameter for comparing PSP formulations at low speeds.

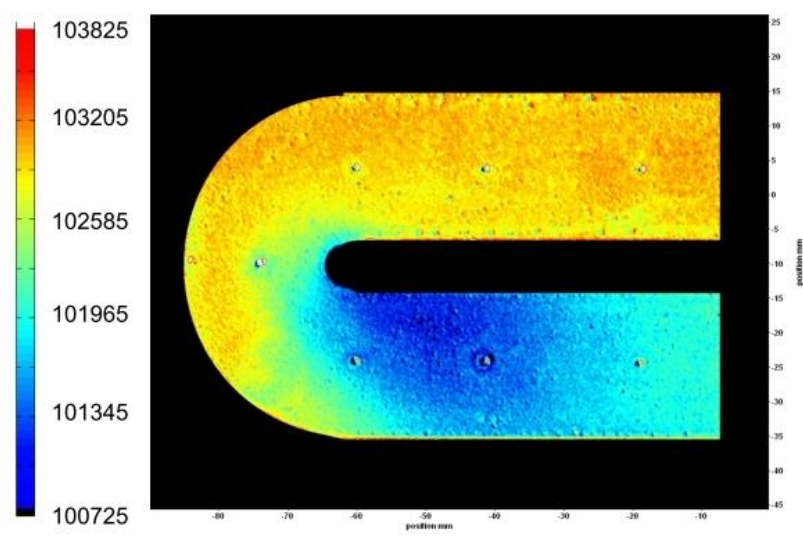

Fig. 6. Pressure map with PtTFPP $1^{\text {st }}$ sample and 3000 $\mathrm{Pa}$ inlet pressure

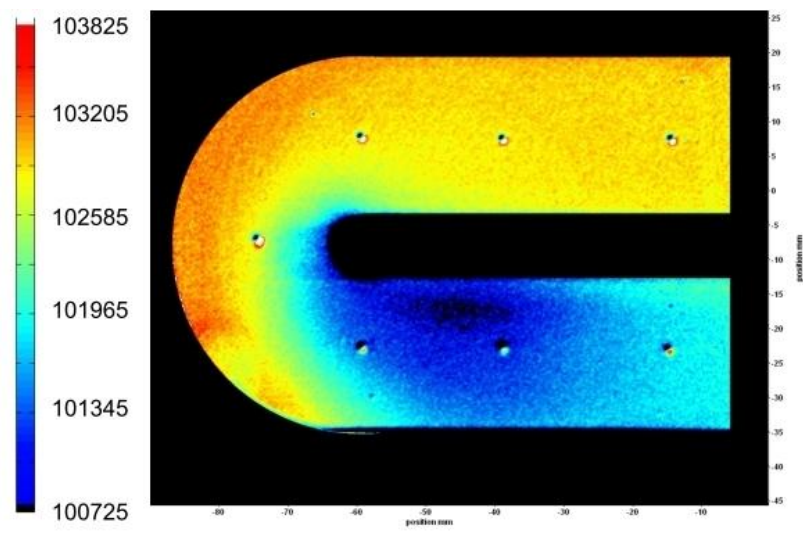

Fig. 7. Pressure map with PtTFPP $2^{\text {nd }}$ sample and 3000 $\mathrm{Pa}$ inlet pressure

The significance of surface roughness and luminophore uniformity is shown when comparing the first and second PtTFPP samples. The reduction of surface roughness between the first and second PtTFPP samples is over fourfold. This is clearly borne out in the results shown. Comparing Figs. 3 and 4 with 5 shows a significant decrease in spatial noise and therefore an increase in the accuracy and reliability of the measurements. This effect is more prominent when comparing whole surface pressure maps. Figs. 6 and 7 show the surface pressure profile with a $3000 \mathrm{~Pa}$ inlet pressure. Both samples shown the expected flow pattern, however, the $2^{\text {nd }}$ sample exhibits a lower degree of spatial noise and larger magnitude pressure changes; indicating a higher sensitivity. To this end, a lower pressure (500 Pa) was tested using this more reliable sample. Although the pressure changes around the bend are as low as $\pm 200 \mathrm{~Pa}$, the expected pattern is still visible, albeit with a larger degree of spatial noise.

The magnitude of the pressure drop measured around the bend varies slightly with PSP formulations and from test 
to test. This is believed to be due to the unfortunate, but unavoidable, temperature sensitivity of the paints. As the flow into the plenum chamber expands, the temperature drops below ambient. As mentioned previously, the rig was allowed to settle for 20 minutes before wind-on image acquisition. As it was necessary to increase the exposure time for the PtTFPP PSP samples, the image acquisition took almost twice as long when compared with the Ru (II) PSP. During the wind-off acquisition the PSP sample is returning to ambient temperature and, due to thermal quenching, giving a lower signal than would be expected. Therefore, the shorter the acquisition time the less temperature-induced error would be expected in wind-off image. The temperature dependency of the paints can be seen by comparing the calibration curves with the windoff image taken before the run and just after shutdown (Fig. 8).

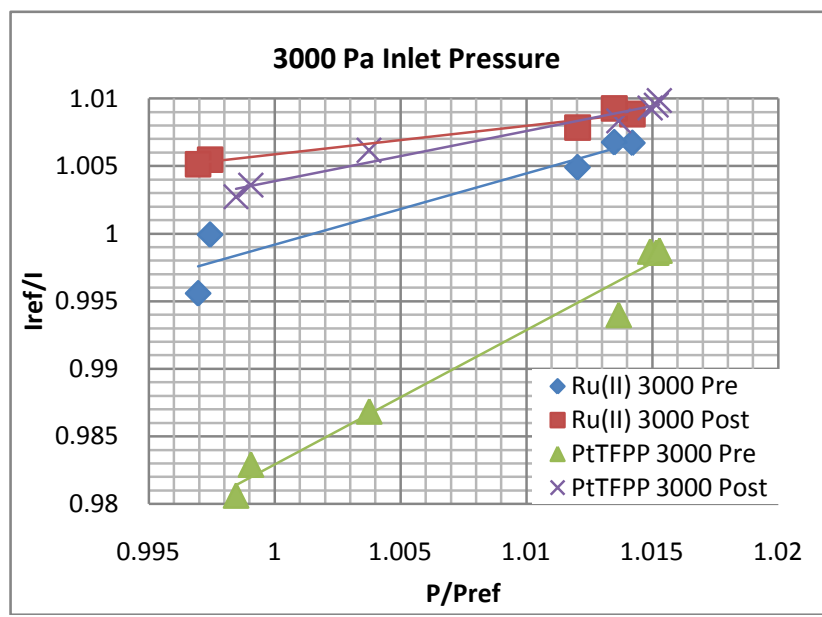

Fig. 8. Calibration curves for Ru (II) and $1^{\text {st }}$ PtTFPP sample at $3000 \mathrm{~Pa}$

The calibration curves shown in Fig. 8 illustrate the difference between taking the wind-off image before and after the wind-on image. From this it is clear to see that PtTFPP has a greater temperature dependency, as its calibration curve has shifted significantly due to the extra thermal quenching present at ambient, as opposed to below ambient, temperature. As mentioned previously insitu calibration removes the temperature induced error providing the temperature change is one discrete step with no spatial variation. The post-test wind-off calibration should be used as the pre-test wind-off calibration does not include any of the temperature gradients that will inevitably be found in the wind-on image. In previous tests conducted at the University of Manchester this has been found to make the paint act more like a temperature sensor than a pressure sensor. This is because the PSP luminophores have a temperature sensitivity of $0 \sim 1 \% /{ }^{\circ} \mathrm{C}$. Clearly Fig. 8 shows that the intensity changes over the small pressure range seen here is of the order of $1 \%$ so minimizing any temperature variations between wind-on and wind-off images is vital.
To increase the accuracy of the calibration curves shown in Fig. 8 it will be necessary to drill more pressure taps into the model around the area of highest pressure gradient, i.e. just after the bend.

\section{CONCLUSION}

The present study has examined the low-speed applicability of PSP developed in-house at the AeroPhysics Lab at the University of Manchester. Both PSP's (tris-Bathophenanthroline Ruthenium Perchlorate (Ru (II)) and Platinum tretakis (pentafluorophenyl) Porphyrin (PtTFPP)) have shown substantial promise in the area. Both luminophores have shown adequate pressure sensitivity. PtTFPP, when applied correctly, has shown to be the better of the two luminophores, with a higher pressure sensitivity and signal-to-noise ratio despite its quantum yield at atmospheric pressure.

The flow features of incompressible flow around a U-bend of sharp curvature have been captured well. The rms value for all the tests was below $\pm 150 \mathrm{~Pa}$. This is similar to the values reported by previous researchers such as Brown $[1,15]$ and Lee et al.[7]. The lowest rms value $( \pm 50 \mathrm{~Pa})$ was found during the $500 \mathrm{~Pa}$ test. This value is one of the lowest reported and it is reasonable to expect that this can be improved upon by optimizing the number of coats, the thickness of each coat and by reducing the temperature sensitivity. The peak absorption wavelength of the PtTFPP luminophore is 390 395nm, however the lamp used in this test was $468 \mathrm{~nm}$. When PtTFPP is excited at its ideal wavelength its quantum yield is several times greater than when excited at higher wavelengths [18]. Further tests should be performed using PtTFPP and an excitation light source made of $395 \mathrm{~nm}$ LEDs to increase the signal to noise ratio of the PSP, helping to detect even smaller pressures.

Previous researchers have used Infra-Red cameras to measure the temperature profile of the PSP sample in order to calibrate out any temperature induced error. Work is currently underway to account for the temperature dependency of PSP. Incorporating a purely temperaturesensitive luminophore, creating a binary paint will account for temperature changes but another method of dynamic calibration is also being explored.

\section{ACKNOWLEDGEMENTS}

The authors would like to thank the technical and administrative staff in the School of MACE at the University of Manchester. Special thanks go to RollsRoyce for loan of the experimental test rig and the EPSRC (Engineering and Physical Sciences Research Council) Engineering Instrument Pool for loan of the Taicaan XYris 4000 surface roughness profiler and the Princeton Instruments ICCD spectrometer. 


\section{REFERENCES}

[1] Brown O C (2000) Low-Speed Pressure Measurements Using A Luminescent Coating System. $\mathrm{PhD}$ thesis, Stanford University

[2] Engler R H, Mérienne M-C, Klein C, Le Sant Y (2002) Application of PSP in low speed flows. Aerospace Science and Technology 6:313-322

[3] Bell J H (2004) Applications of Pressure-Sensitive Paint to Testing at Very Low Speed Flows. 42 ${ }^{\text {nd }}$ AIAA Aerospace Sciences Meeting and Exhibit, Reno, Nevada, United States 5-8 January 2004

[4] Le Sant Y, Mérienne M-C (2005) Surface pressure measurements by using pressure-sensitive paints. Aerospace Science and Technology 9:285-299

[5] Mitsuo K, Kurita M, Nakakita N, Watanabe S (2005) Temperature Correction of PSP Measurement for Low-Speed Flow Using Infrared Camera. $21^{\text {st }}$ International Congress on Instrumentation in Aerospace Simulation Facilities, Sendai, Japan

[6] McGraw C M, Bell J H, Khalil G, Callis J B (2006) Dynamic surface pressure measurements on a square cylinder with pressure sensitive paint. Experiments in Fluids 40:203-211

[7] Lee J K, Ko J, Kim S (2010) Pressure Sensitive Paint Application in ADD Low Speed Wind Tunnel. $14^{\text {th }}$ International Symposium on Flow Visualization, Daegu, Korea, 21-24 June 2010

[8] Rowe M (1970) Measurement and computations of flow in pipe bends. Journal of Fluid Mechanics, 43(4):771-783

[9] Iacovides H, Launder B E, Li H Y (1996) The computation of flow development through stationary and rotating $\mathrm{u}$-ducts of strong curvature. International Journal of Heat and Fluid Flow, 17(1):22-33

[10] Berger S A, Talbot L, Yao L A (1983) Flow in curved pipes. Annual Review of Fluid Mechanics, 15:461512

[11]Fried E, Idelchik I E (1989) Flow Resistance: A Design Guide for Engineers. CRC Press

[12] Namgoong H, Son C, Ireland P (2008) U-bend shaped turbine blade cooling passage optimization. AIAA/ISSMO Multidisciplinary Analysis and Optimization Conference, Victoria, British Columbia, Canada, 10-12 September 2008

[13]Lui T, Sullivan J P (2005) Pressure and Temperature Sensitive Paints. Springer-Verlag, Berlin

[14] Gouterman M (1997) Oxygen Quenching of Luminescence of Pressure Sensitive Paint for Wind Tunnel Research. Journal of Chemical Education 74(6):697-702

[15] Brown O C, Mehta R D, Cantwell B J (1997) Lowspeed flow studies using the pressure sensitive paint technique. Advanced Aerodynamic Measurement Technology Symposium, Seattle, Washington, United States 22-25 September 1997

[16] Basu B J (2007) Optical Oxygen Sensing Based on Luminescence Quenching of Platinum Porohyrin
Dyes Doped in Ormosil Coatings. Sensors and Actuators B 123:568-577

[17]Zare-Behtash H, Gongora-Orozco N and Kontis K (2009) PSP Visualization on a Convergent Nozzle with an Ejector System. Journal of Visualization 12 (2):157-163

[18] Puklin E, Carlson B, Gouin S, Costin C, Green E, Ponomarev S, Tanji H, Gouterman M (2000) Ideality of Pressure-Sensitive Paint. I. Platinum Tetra(pentafluorophenyl)porphine in Fluoroacrylic Polymer. Journal of Applied Polymer Science 77(13):2791-2804 